
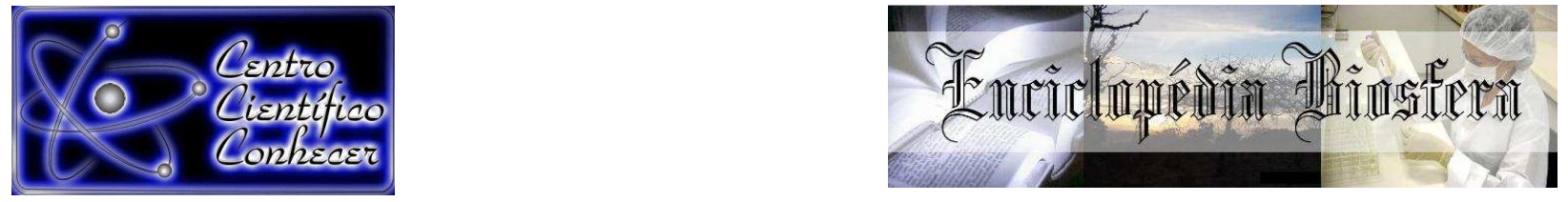

\title{
AVALIAÇÃO DE SEMEADORA ADUBADORA PNEUMÁTICA ANALISANDO ESPAÇAMENTOS ENTRE PLANTAS E PRODUTIVIDADE
}

\footnotetext{
Étore Francisco Reynaldo ${ }^{1}$, Thiago Martins Machado ${ }^{2}$, Leandro Taubinger ${ }^{3}$, Dionathan de Quadros ${ }^{4}$ Sascha Ronny Scwartz ${ }^{5}$

${ }^{1}$ Pesquisador da Fundação Agrária de Pesquisa Agropecuária (etorereynaldo@hotmail.com) - Guarapuava - PR - Brasil

${ }^{2}$ Professor Adjunto do Instituto de Ciências Agrárias e Ambientais da Universidade Federal de Mato Grosso - Sinop - MT - Brasil

${ }^{3}$ Mestrando em Produção Vegetal na Unicentro - Guarapuava - PR - Brasil

${ }^{4}$ Engenheiro Agrônomo e Auxiliar técnico da Fundação Agrária de Pesquisa Agropecuária - Guarapuava - PR - Brasil

${ }^{5}$ Trainee de processos, Cooperativa Agrária Agroindustrial -Guarapuava- PR Brasil
}

Recebido em: 08/04/2016 - Aprovado em: 30/05/2016 - Publicado em: 20/06/2016 DOI: 10.18677/Enciclopedia_Biosfera_2016_014

\begin{abstract}
RESUMO
O milho está entre os cereais mais importantes atualmente cultivados no Brasil, sendo uma fonte energética de alimentação, que impulsiona a economia em vários estados brasileiros. A velocidade é um fator determinante na semeadura do milho, para uma boa produtividade. Objetivou-se com este trabalho estudar o fator velocidade na semeadura do milho em uma semeadora com mecanismo dosador pneumático. O delineamento experimental foi em blocos ao acaso, com quatro repetições e com seis diferentes velocidades $2,4,6,8,10$ e $12 \mathrm{~km} \mathrm{~h}^{-1}$ As variáveis mensuradas foram: espaçamentos múltiplos, falhos, aceitáveis e a produtividade. $\mathrm{O}$ incremento na velocidade da semeadora contribuiu para o aumento das variáveis: falhos e múltiplos e redução dos espaçamentos aceitáveis e como consequência queda da produtividade do milho. A velocidade do conjunto que apresentou a maior produtividade no milho foi de $4 \mathrm{~km} \mathrm{~h}^{-1}$.
\end{abstract}

PALAVRAS-CHAVE: espaçamentos normais, máquinas agrícolas, semeadora

\section{SEEDER EVALUATION OF PNEUMATIC ANALYZING SEEDS PRODUCTIVITY AND INDEX}

\begin{abstract}
Corn is among the most important cereals currently grown in Brazil, an energy power supply that drives the economy in several Brazilian states. The speed is a determining factor in corn sowing for good productivity. The objective of this work was to study the speed factor in corn sowing in a seed drill with pneumatic metering system. The experimental design was a randomized block with four replications and six different speeds $2,4,6,8,10$ and $12 \mathrm{~km} \mathrm{~h}^{-1}$ The variables measured were: multiple spacings, flawed, acceptable and productivity. The increase in the speed of seeder contributed to the increase of variables: skips and multiples and reduction of
\end{abstract}


acceptable spacings and consequently decrease the yield of corn. The speed of the set with the highest productivity in corn was $4 \mathrm{~km} \mathrm{~h}^{-1}$.

KEYWORDS: Sowing, feed index, agricultural machinery

\section{INTRODUÇÃO}

Dentre os cereais cultivados no Brasil, o milho é o mais expressivo, com cerca de 78 milhões de toneladas de grãos produzidos, em uma área de aproximadamente 15 milhões de hectares, referentes a duas safras: normal e safrinha conforme CONAB (2015), por suas características fisiológicas, a cultura do milho tem alto potencial produtivo, já tendo sido obtidos no Brasil produtividades superiores a 16 ton ha ${ }^{-1}$, o cereal além de ser utilizado na alimentação humana, pode também ser utilizado para fabricação de rações animais e como fonte energética (EMBRAPA ,2016).

Sendo o desempenho, a tecnologia e a qualidade da semeadora de fundamental importância, para manter a qualidade na uniformidade da cultura, e consequentemente, obter uma boa produtividade (SOUZA JUNIOR \& CUNHA, 2012). A semeadura é uma das etapas que exigem maior perfeição em sua execução, pois pode comprometer a lucratividade da atividade agrícola (ROS et al., 2011). Segundo MIALHE (2012), as semeadoras de precisão mais utilizadas no Brasil, são as que apresentam sistemas dosadores: com discos alveolados horizontais, e com dosadores pneumáticos de sucção (vácuo). Dependendo do sistema dosador de sementes e a velocidade de operação, poderá influenciar na relação dos espaçamentos entre plantas.

A qualidade na distribuição longitudinal das sementes está relacionada com o ângulo de repouso das sementes no depósito, o teor de água, a presença de material estranho, a orientação das partículas e, principalmente, a rugosidade da superfície da semente (GARCIA et al., 2006).

A distribuição de sementes de uma semeadora, pode ser afetada com a elevação da velocidade da máquina, pois ocorre a diminuição do número de espaçamentos aceitáveis e aumento das falhas (SANTOS et al., 2011). Já CASTELA JUNIOR et al. (2014) discordam, afirmando que incremento da velocidade de semeadora com mecanismo dosador pneumático não interferiu na distribuição longitudinal de sementes e nem na produtividade.

Estudando vários trabalhos sobre o assunto, observa-se uma grande divergência de resultados sobre a influência da velocidade de semeadura, em máquinas, com mecanismo dosador pneumático. Sendo assim, objetivou-se avaliar a influência da velocidade em uma semeadora com mecanismo dosador pneumático, na semeadura do milho.

\section{MATERIAL E MÉTODOS}

O trabalho foi realizado na Agropecuária Scherer, município de Guarapuava PR. Situada na seguinte coordenada geográfica central: latitude -2521'14.97" e longitude - 51938'17.83".

O híbrido de milho utilizado foi o P30F53H. No quadro 1 são apresentados os tratamentos utilizados no ensaio de influência de diferentes velocidades de semeadura. 
QUADRO 1 - Tratamentos avaliados

\begin{tabular}{cc}
\hline Número Tratamento & Descrição \\
\hline 1 & Semeadura a $2 \mathrm{~km} \mathrm{~h}^{-1}$ \\
2 & Semeadura a $4 \mathrm{~km} \mathrm{~h}^{-1}$ \\
3 & Semeadura a $6 \mathrm{~km} \mathrm{~h}^{-1}$ \\
4 & Semeadura a $8 \mathrm{~km} \mathrm{~h}^{-1}$ \\
5 & Semeadura a $10 \mathrm{~km} \mathrm{~h}^{-1}$ \\
6 & Semeadura a $12 \mathrm{~km} \mathrm{~h}^{-1}$ \\
\hline
\end{tabular}

Para a semeadura foi utilizada a semeadora marca Jumil ${ }^{\circledR}$, modelo: JM 2980 PD EX 10, com sistema dosador de sementes pneumático. A semeadora foi acoplada a um trator da marca John Deere, modelo: 6600. A semeadura ocorreu em $28 / 09 / 2012$, o solo estava com $28 \%$ de teor de água. As avaliações de espaçamentos falhos, múltiplos e aceitáveis foram realizadas conforme a ISO $7256 / 1$ (ISO, 1984) pelo percentual de espaçamentos falhos ( $\geq 1,5$ vezes 0 espaçamento nominal), múltiplos ( $\leq 0,5$ vezes o espaçamento nominal) e os demais foram classificados como aceitáveis.

Foram considerados 250 espaçamentos, ao longo de três fileiras de semeadura e para a determinação da produtividade foram colhidas quatro fileiras por 5 metros de comprimento, totalizando $14 \mathrm{~m}^{2}$, ambas as avaliações possuíam 12 repetições. A estatística foi analisada pelo programa SAS 9.3, sendo comparadas pelo teste Tukey ao nível de $5 \%$.

\section{RESULTADOS E DISCUSSÃO}

$\mathrm{Na}$ Figura 1 são apresentados os dados referentes aos espaçamentos falhos nas diferentes velocidades de avanço da semeadora. A velocidade de $12 \mathrm{~km} \mathrm{~h}^{-1}$ apresentou $16,7 \%$ de espaçamentos falhos, seguido das velocidades de 10 e $8 \mathrm{~km}$ $\mathrm{h}^{-1}$ com 11,4 e $8,6 \%$ de espaçamentos falhos. As velocidades menores apresentaram os menores valores de espaçamentos falhos com 4,$4 ; 4,3$ e 3,9\% para as velocidades de 6,4 e $2 \mathrm{~km} \mathrm{~h}^{-1}$.

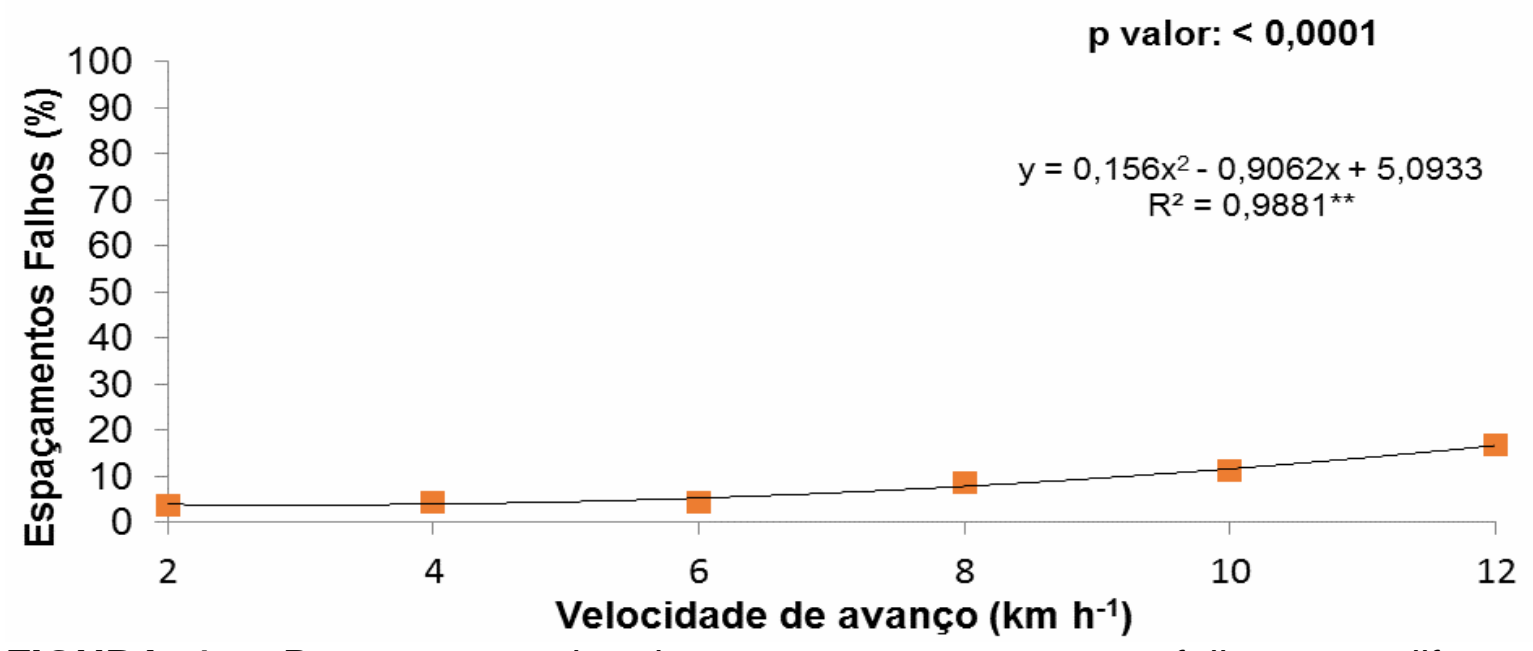

FIGURA 1 - Porcentagem de plantas em espaçamentos falhos em diferentes velocidades da semeadora.

**Médias seguidas de mesma letra não se diferenciam estatisticamente pelo teste t ao nível de $5 \%$ e $1 \%$ respectivamente. 
Na Figura 2 são apresentados os resultados da avaliação de distribuição de plantas para o atributo de espaçamentos múltiplos. O mesmo comportamento observado para o atributo de espaçamentos falhos foi também evidenciado para os espaçamentos múltiplos. Ou seja, com o aumento da velocidade houve aumento significativo de múltiplos. As maiores porcentagens de falhas foram observadas para as velocidades de 12, 10 e $8 \mathrm{~km} \mathrm{~h}^{-1}$, com 14,3; 11,5 e 6,1\% de plantas múltiplas. Os resultados corroboram com os resultados de GARCIA et al. (2006) nos quaisl o aumento da velocidade da semeadora, proporcionou um aumento de espaçamentos falhos e múltiplos e queda de espaçamentos normais. Os resultados contrariam os valores encontrados por CASTELA JUNIOR et al. (2014), segundo estes autores o aumento da velocidade não influencia na qualidade dos espaçamentos.

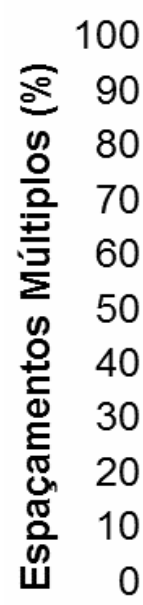

FIGURA 2 - Porcentagem de plantas em espaçamentos múltiplos em diferentes velocidades da semeadora.

*Médias seguidas de mesma letra não se diferenciam estatisticamente pelo teste $t$ ao nível de $5 \%$.

Na Figura 3 são apresentados os resultados em porcentagem de plantas em espaçamentos aceitáveis nas diferentes velocidades de avanço da semeadora.

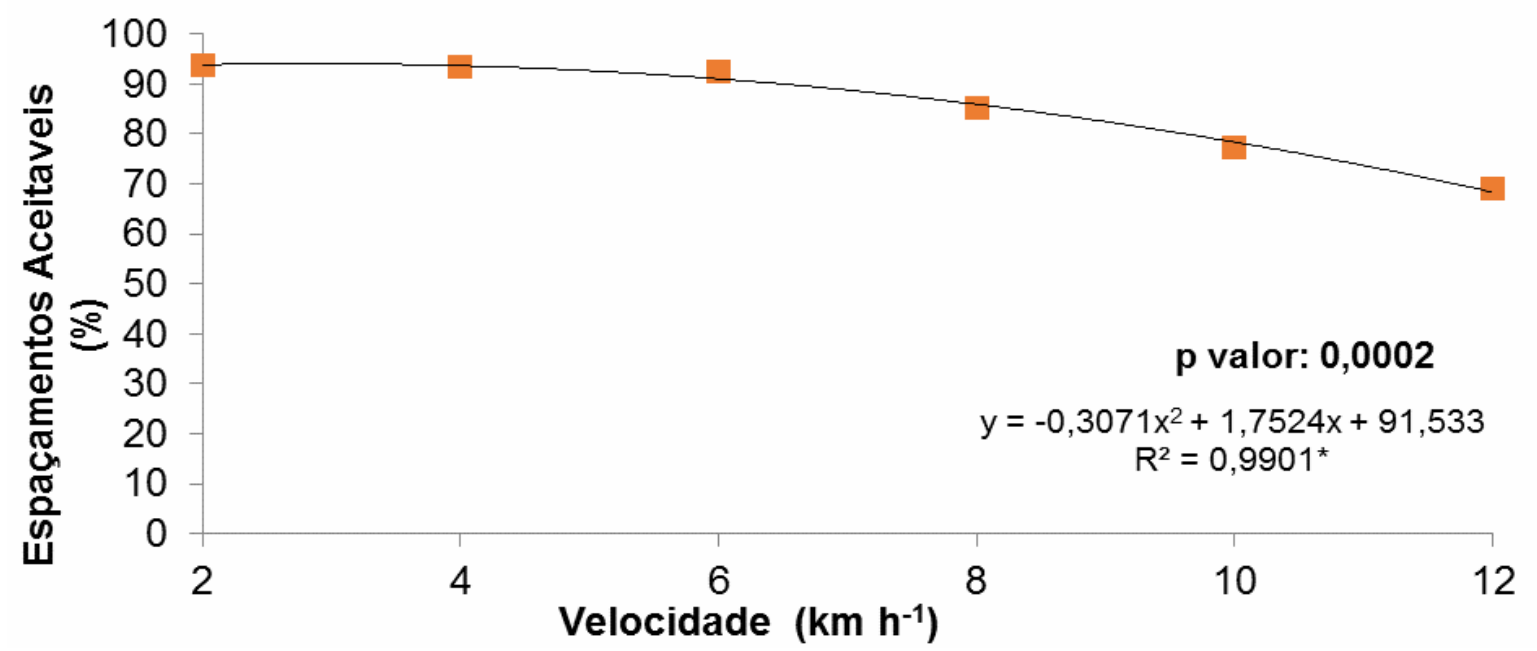

FIGURA 3 - Porcentagem de plantas em espaçamentos aceitáveis em diferentes velocidades da semeadora.

*Médias seguidas de mesma letra não se diferenciam estatisticamente pelo teste $t$ ao nível de $5 \%$. 
De acordo com COELHO (1996) a recomendação de espaçamentos normais ou aceitáveis é de $90 \%$, para uma boa expectativa de produtividade. Neste contexto, somente as velocidades de 2, 4 e $6 \mathrm{~km} \mathrm{~h}^{-1}$ apresentam níveis satisfatórios de eficiência, apresentando 93,6; 93,3 e 92,6\% de espaçamentos normais para as respectivas velocidades.

Analisando os valores médios de espaçamentos normais, falhos e múltiplos em 32 avaliações de semeadura executadas na cultura do milho REYNALDO et al. (2015) obtiveram os seguintes resultados: $89,6 \%$ de espaçamentos normais, $6,4 \%$ de espaçamentos múltiplos e $4 \%$ de espaçamentos falhos. Sendo os resultados obtidos no ensaio nas baixas velocidades 2 e $4 \mathrm{~km} \mathrm{~h}^{-1}$, superiores aos resultados dos autores citados (Figuras 1,2,3).

$\mathrm{Na}$ Figura 4 são apresentados os rendimentos da cultura de acordo com as velocidades de semeadura. A maior produtividade foi obtida na velocidade de $4 \mathrm{~km}$ $\mathrm{h}^{-1}$, com $15.919 \mathrm{~kg} \mathrm{ha}^{-1}$. Contudo, não se diferenciou estatisticamente ao nível de $5 \%$ de probabilidade das velocidades de 2, 6 e $8 \mathrm{~km} \mathrm{~h}^{-1}$, com produtividade de 15,269, 14,660 e $14,583 \mathrm{~kg} \mathrm{ha}^{-1}$. Conforme as afirmações de TROGELLO et al. (2013), também não encontraram diferenças de produtividade com aumento das velocidades de semeadura.

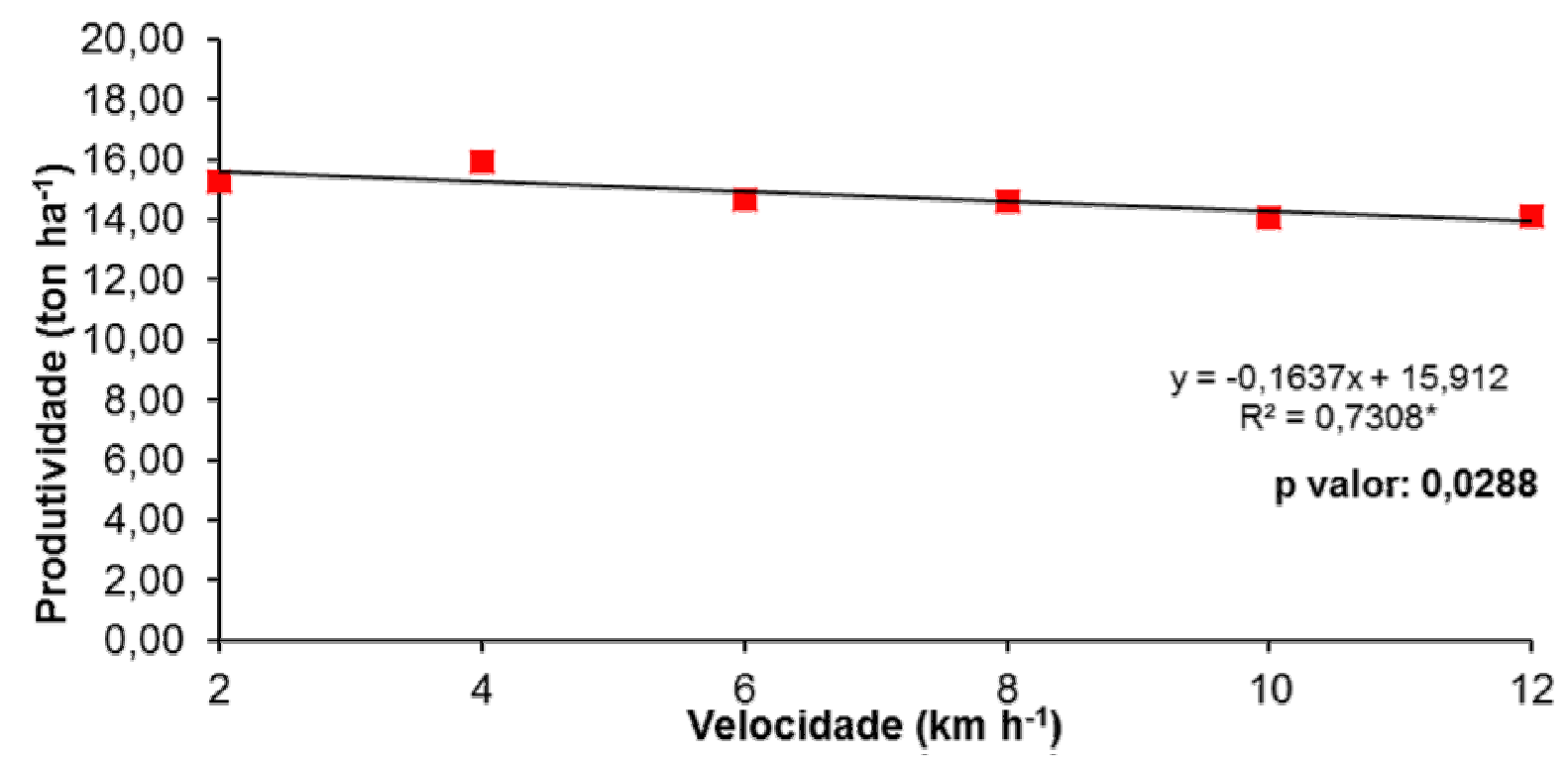

FIGURA 4 - Produtividade em relação a velocidade de semeadura.

*Médias seguidas de mesma letra não se diferenciam estatisticamente pelo teste $t$ ao nível de $5 \%$.

Quando comparado aos rendimentos nas diferentes velocidades da semeadura, tem-se redução gradativa com o incremento da velocidade (Figura 5). Tomando por base o maior rendimento de grãos, a redução de produtividade pode chegar a $11,8 \%$ em velocidades mais elevadas de plantio.

Houve redução de produtividade em velocidades menores, como a $2 \mathrm{~km} \mathrm{~h}^{-1}$, com 4,1\%. Dentre as possíveis explicações, a mais provável é do erro experimental, pois estatisticamente não houve diferenças entre as velocidades de 2, 4 e $6 \mathrm{~km} \mathrm{~h}^{-1}$. Por outro lado, para que o mecanismo apresente boa regularidade de dosagem e distribuição de sementes é necessário que haja velocidade angular constante do disco dosador, além de velocidades de avanço baixo, pode reduzir o nível de 
vibrações na semeadora, o que por sua vez, poderá reduzir a fluidez das sementes no reservatório.

Analisando as velocidades de forma geral, pode-se dizer que as velocidades de 4 a $6 \mathrm{~km} \mathrm{~h}^{-1}$ são as mais indicadas para se realizar a operação de semeadura. Pois, no processo tem que se levar em conta não somente a questão de máxima eficiência, mas também, o de rendimento operacional. Então, quanto mais próximo da velocidade de $4 \mathrm{~km} \mathrm{~h}^{-1}$ maior a eficiência de distribuição de plantas e, quando mais próximos da velocidade de $6 \mathrm{~km} \mathrm{~h}^{-1}$ maior o rendimento operacional. Ficando a cargo do usuário a decisão de que velocidade vai realizar a operação de plantio.

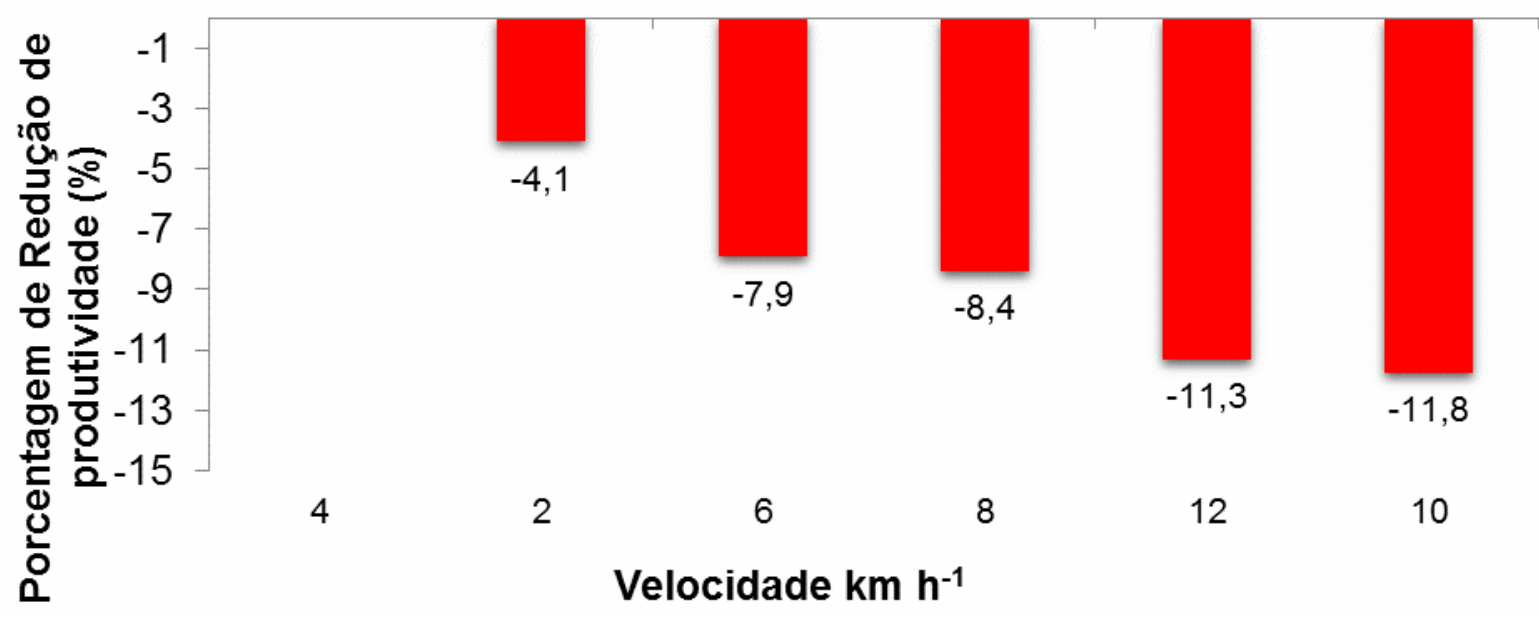

FIGURA 5 - Comparativo da redução de produtividade versus aumento da velocidade da semeadora.

As semeadoras adubadoras em menores velocidades melhoram o contato solo-semente e predispõem as mesmas às melhores condições de temperatura e umidade para a emergência, tendo contribuição para melhoria da produtividade. Porém um fato preocupante diz respeito as recomendações de velocidade de avanço que as novas semeadoras, principalmente as de grande capacidade operacional (> 32 linhas de plantio) vem sendo sugeridas pelos fabricantes. É comum ouvir fabricantes recomendando velocidade de deslocamento superior a 10 $\mathrm{km} \mathrm{h}^{-1}$, assim, e se baseando nos dados apresentados, pode-se afirmar que está havendo prejuízo significativo com impacto direto no rendimento da cultura de milho semeada em velocidades superiores.

\section{CONCLUSÕES}

O aumento da velocidade implica em aumento dos espaçamentos falhos, múltiplos e redução de espaçamentos aceitáveis. 1

A velocidade que apresentou a maior produtividade foi a velocidade de $4 \mathrm{~km} \mathrm{~h}$

Velocidades acima dos $6 \mathrm{~km} \mathrm{~h}^{-1}$ ocasionam redução de produtividade de até $11,8 \%$, em consequência aos aumentos de sementes em espaçamentos falhos e múltiplos. 


\section{REFERÊNCIAS}

CASTELA JUNIOR, M. A. ; OLIVEIRA, T. C.; FIGUEIREDO, Z. N.; SAMOGIM, E. M.; CALDEIRA, D. S. A. Influência da velocidade da semeadora na semeadura direta da soja. Enciclopédia Biosfera, Goiânia, v. 10, n. 19, p. 1199-1207, 2014. Disponível em:<http://www.conhecer.org.br/enciclop/2014b/AGRARIAS/influencia\%20da\%20vel ocidade.pdf >. Acesso em: 28 janeiro. 2016.

COELHO, J.L.D. Ensaio e certificação de máquinas para a semeadura. In: MIALHE, L.G. Máquinas agrícolas: ensaio e certificação. Piracicaba: Fundação de Estudos Agrários "Luiz de Queiroz", 1996. p.55-70.

CONAB - Companhia Nacional de Abastecimento. Disponível em:< http://www.conab.gov.br>. Acesso em: 09 março 2016.

EMBRAPA - Empresa Brasileira de Pesquisa Agropecuária. Disponível em:< https://www.embrapa.br> . Acesso em: 08 março 2016.

GARCIA, I. C.; JASPER, R.; JASPER, M.; FORNARI, A.J.; BLUM, J. Influência da velocidade de deslocamento na semeadura do milho Engenharia Agrícola, v.26, n.2, p.520-527, 2006.

INTERNACIONAL ORGANIZATION FOR ESTANDARDIZATION. ISO 7256/1: Sowing equipment -Methods of test - Part 1: Single seed drills (precision drills).Genève, 1984. 16p.

MIALHE, L.G. Máquinas agrícolas para plantio. São Paulo: Millennium. 623p 2012.

REYNALDO, E. F.; MACHADO, T. M.; TAUBINGER, L.; QUADROS, D. Avaliação da qualidade de semeadura de milho e soja na região centro sul do estado do paraná Enciclopédia Biosfera, v.11, n.22, p.417-426. 2015. Disponível em: < http://www.conhecer.org.br/enciclop/2015c/agrarias/avaliacao\%20da\%20qualidade.p df>. Acesso em: 22 janeiro. 2016. Doi: http://dx.doi.org/10.18677/Enciclopedia_Biosfera_2015_095

ROS, V.V.; SOUZA, C.M.A.; VITORINO, A.C.T.; RAFULL, L.Z.L. Oxisol resistence to penetration in no-till system after sowing. Engenharia Agrícola, Jaboticabal, v. 31, n. 6 , p. 1104-1114, 2011.

SANTOS, A. J.; C.A. GAMERO, R.B. OLIVEIRA.; A.C. VILLEN. 2011. Análise espacial da distribuição longitudinal de sementes de milho em uma semeadoraadubadora de precisão. Bioscience Journal, v. 27, n. 01, p.16-23, 2011.

SOUZA JUNIOR, R. L.; CUNHA, J. P. A. R. Desempenho de uma semeadora de plantio direto na cultura do milho. Revista Agrotecnologia, Anápolis, v.3, n.1, p. 8190, 2012.

TROGELLO, E.; MODOLO, A. J.; SCARSI, M.; SILVA, C. L.; ADAMI, P. F.;DALLACORT, R. Manejos de cobertura vegetal e velocidades de operação em 
condições de semeadura e produtividade de milho. Revista Brasileira de Engenharia Agrícola e Ambiental. v. 17, n. 7, p. 796-802, 2013. 